\title{
Comparison of the promotion effects on sulfated mesoporous zirconia catalysts achieved by alumina and gallium
}

\author{
Chi-Chau Hwang ${ }^{\mathrm{a}}$, Chung-Yuan Mou ${ }^{\mathrm{a}, \mathrm{b}, *}$ \\ a Department of Chemistry, National Taiwan University, Taipei 106, Taiwan \\ ${ }^{\mathrm{b}}$ Center of Condensed Matter Science, National Taiwan University, Taipei 106, Taiwan
}

\section{A R T I C L E I N F O}

\section{Article history:}

Received 8 April 2009

Received in revised form 4 June 2009

Accepted 4 June 2009

Available online 11 June 2009

\section{Keywords:}

Butane isomerization

Mesoporous

Sulfated zirconia

Alumina

Gallium

Oxidative dehydrogenation

\begin{abstract}
A B S T R A C T
Mesoporous zirconia, hydrothermally synthesized from surfactant templating, was directly impregnated with aluminum sulfate or gallium sulfate to give the solid acids, Al- and Ga-promoted sulfated mesoporous zirconia catalysts (AS/MP-ZrO 2 and GS/MP- $\mathrm{ZrO}_{2}$ ). The promotional effects achieved by these two catalysts for the $n$-butane isomerization were compared to clarify the differences in mechanism in catalytic activities in butane isomerization. The catalysis was found to be strongly promoted by the addition of a proper amount of alumina or gallium. The activities of Ga-promoted catalysts were higher than those of Al-promoted catalysts. Diffuse-reflectance infrared Fourier-transformed (DRIFT) spectra and temperature programmed desorption mass (TPD-MS) analyses were employed to identify and quantify properties of the acid sites on catalyst surfaces. The $3 \mathrm{AS} / \mathrm{MP}-\mathrm{ZrO}_{2}$ catalyst shows a slightly higher acidity in strength and amount than that of $3 \mathrm{GS} / \mathrm{MP}-\mathrm{ZrO}_{2}$, but much higher than that of the unpromoted $3 \mathrm{~S} / \mathrm{MP}-\mathrm{ZrO}_{2}$ catalyst. All three catalysts were further compared in their redox properties, with the $\mathrm{H}_{2}$-temperature programmed reduction (TPR) analysis showing totally different tendencies (redox ability: $3 \mathrm{GS}>3 \mathrm{~S}>3 \mathrm{AS} / \mathrm{MP}-\mathrm{ZrO}_{2}$ ). A small concentration of olefins accompanied with water formation were observed by in situ DRIFT spectra and quantified by the Baeyer test. The results show that this occurs via oxidative dehydrogenation of butane by the sulfate groups to form butene, which leads to butyl carbenium species for skeleton isomerization. The catalytic promotion effect of alumina on sulfated zirconia is mainly due to a balanced increase of acid sites; on the other hand, gallium promotes sulfated zirconia through enhancing both the surface acidity and its redox properties on the surface.
\end{abstract}

(c) 2009 Elsevier B.V. All rights reserved.

\section{Introduction}

Skeletal isomerization of normal alkane to branched alkanes by using solid acid catalysts is one of the important technologies for RON improvement in oil refining [1,2]. Traditionally, the solid acids employed are either chlorided alumina or Pt-mordenite catalysts. For chlorided alumina, constant addition of chloride is necessary and its disposal is often environmentally damaging. For Ptenhanced zeolites, the disadvantage is the relatively high operating temperature which leads to poor RON results. Since the discovery of its strong acidity, sulfated zirconia (SZ) has attracted much attention as a promising isomerization catalyst thanks to its high activity and environmental friendliness. However, promoters are needed for a steady and high activity. It is generally accepted that the noble metal Pt is an adequate promoter in the sulfated zirconia catalyst (SZ) for the skeleton

\footnotetext{
* Corresponding author at: Department of Chemistry, National Taiwan University, Taipei 106, Taiwan.

E-mail address: cymou@ntu.edu.tw (C.-Y. Mou).
}

isomerization of $n$-alkane [1]. The addition of $\mathrm{Pt} / \mathrm{H}_{2}$ improved the stability of $\mathrm{SO}_{4}{ }^{2-} / \mathrm{ZrO}_{2}$ catalyst and reduced coke formation. Currently $\mathrm{Pt} / \mathrm{SZ}$ is the basis of commercial C5-C6 naphtha isomerization processes like the Par-Isom (UOP). However, the high cost of Pt and its high sensitivity to sulfur in the feed gas make searching for alternative promoters desirable. Lately, the promotion effect of main group metals (alumina or gallium) [2,3] on SZ in the isomerization reaction of $n$-alkanes has received much attention, for it simultaneously promoted and stabilized activity without the use of Pt [4-9]. The promotion and stabilization effects of $\mathrm{Al}$ or $\mathrm{Ga}$ on sulfated zirconia in $n$-alkane isomerization without using the expensive Pt are technologically very attractive.

An interesting observation is that, although $\mathrm{Al}$ and $\mathrm{Ga}$ belong to the same group in the periodic table and both exhibit excellent promoting effects in the catalysis of $n$-alkane isomerization, their promoting mechanisms may be quite different [8]. Gao and coworkers [10] attributed the catalytic promotion effect of $\mathrm{Al}$ on SZ to an increase of acid sites. We previously reported that the remarkable activity and stability of Al-promoted SZ catalysts are due to the balanced distribution of acid site strengths with an enhanced amount of weak Brønsted acid sites [11]. On the other 
hand, Ga-containing zeolite is known to catalyze the oxidative dehydrogenation reaction of alkanes [12]. Ga-promoted SZ catalyst shows an enhancement of its redox properties [8].

For a long time, the main active sites of SZ for the catalytic isomerization of $n$-alkane have been considered to be its acid sites, and indeed a balanced distribution of acid sites strength was proven to be crucial to enhance activity and stability of the Alpromoted SZ catalyst [11]. However, this concept should be further modified according to recent studies of the redox properties of sulfated zirconia. SZ catalyst not only plays the role of solid acid, but it was also shown to initiate the catalytic cycle by dehydrogenation to an olefin, which then forms a carbenium ion for the chain initiation $[13,14]$. So, in view of the recent deeper understanding of the redox property of SZ, we would like to investigate the roles of promoters especially in the promotion of redox reaction. In a recent study, we found that the doping of alumina onto sulfated zirconia increases the extent of sulfur retention on the surface of zirconia, which then promotes the oxidative dehydrogenation of butane to butene and the initiation of skeleton isomerization [15]. By analyzing the distribution of products, we also proposed a detailed mechanism to clarify the multiple roles of $\mathrm{Al}$ in $\mathrm{Al}$-promoted SZ.

Based on these new understandings, it would be interesting to compare the promotional effects of $\mathrm{Al}$ and $\mathrm{Ga}$ on SZ catalyst. In a previous report, it was shown that the activity of Ga-promoted SZ catalyst gave a higher value than that of Al-promoted catalyst [8]. It was also concluded that Ga promotes SZ in a different way from $\mathrm{Al}$ promotion of SZ catalyst. However, there was no detailed understanding of the origins of the promotional effects.

In this paper, we would like to compare in details the promotional effects of $\mathrm{Ga}$ and $\mathrm{Al}$ on the SZ catalysis in butane isomerization. For the purpose of gaining larger surface area, we primarily use a special form of zirconia-mesoporous zirconia (named as $\mathrm{MP}-\mathrm{ZrO}_{2}$ ) which is synthesized by templating micelles of CTAB $[11,16]$. We are going to focus on the Ga-promoted sulfated mesoporous zirconia catalyst (denoted as GS/MP-Z $\mathrm{ZrO}_{2}$ ) and compare it with the promoting effects of $\mathrm{Al}$ on sulfated mesoporous zirconia $\left(\mathrm{AS} / \mathrm{MP}-\mathrm{ZrO}_{2}\right)$ in the isomerization of $n$ butane. The two catalysts differ only in the precursor of promoters while the solid acid used is the same, e.g. sulfated mesoporous zirconia. $\mathrm{Ga}_{2}\left(\mathrm{SO}_{4}\right)_{3}$ was replaced by nearly the same amount of $\mathrm{Al}_{2}\left(\mathrm{SO}_{4}\right)_{3}$ (in mol\%). In addition to the information about identification and relative quantification of acid sites on catalyst surfaces after chemisorption of probe molecules, other characterization techniques, such as TPR, in situ DRIFTs, and Baeyer tests of olefin were used to investigate these two different promoters in SZ catalyst.

\section{Experimental}

\subsection{Catalyst preparation}

The mesoporous $\mathrm{ZrO}_{2}$ (named as $\mathrm{MP}-\mathrm{ZrO}_{2}$ ) was synthesized by the surfactant-assisted route, as in the previous report [16]. An ordered mesoporous $\mathrm{ZrO}_{2}$ material loaded with aluminum sulfate (AS/MP-ZrO ${ }_{2}$, Hayashi, Osaka), gallium sulfate $\left(\mathrm{GS} / \mathrm{MP}-\mathrm{ZrO}_{2}\right.$, Acrös), and ammonium sulfate (S/MP-ZrO ${ }_{2}$, Acrös) was prepared via incipient wetness impregnation: the required quantity of each source dissolved in $75 \%$ (vol.\%) alcohol solution was impregnated by the as-synthesized mesoporous zirconia-containing surfactant. The slurry was stirred for $5 \mathrm{~h}$ and oven-dried at $100^{\circ} \mathrm{C}$ overnight. All the catalysts were calcined at $400{ }^{\circ} \mathrm{C}$ for $5 \mathrm{~h}$ to eliminate the template and then at $630^{\circ} \mathrm{C}$ for $5 \mathrm{~h}$ to obtain the tetragonal phase of zirconia (in static air with a heating ramp of $3{ }^{\circ} \mathrm{C} / \mathrm{min}$ ). For the purpose of comparison, a conventional dense-phase catalyst (GS/ZNP) was also prepared with similar loadings of Ga and $S$ but without the template. In the case of GS/Z-NP, amorphous zirconium hydroxide was used instead of the uncalcined MP$\mathrm{ZrO}_{2}$ precursor. Here, Z-NP represents dense-phase zirconia nanoparticles.

\subsection{Characterization techniques}

Elemental analysis was conducted by inductively coupled plasma atomic emission spectroscopy (ICP-AES) using a Jarrel-Ash ICAP 9000 instrument. Carbon analysis was done with a Heraeus VarioEL-III instrument.

In situ diffuse-reflectance infrared Fourier-transformed (DRIFT) spectra of ammonia chemisorbed on catalyst were taken with a Thermo Nicolet 380 FTIR spectrometer. The sample was first dried at $400{ }^{\circ} \mathrm{C}$ for at least $1 \mathrm{~h}$ prior to butane adsorption. The adsorption process was done by flowing butane gas ( $\geqq 99.9 \%$, San-Fu) through the catalyst at $50{ }^{\circ} \mathrm{C}$ for $5 \mathrm{~min}$ and the system was then flushed with dry $\mathrm{N}_{2}$ for $10 \mathrm{~min}$. The catalyst with adsorbed butane molecules was then subjected to a desorption process at increasing temperatures. Spectra were recorded after the catalyst's temperature was held for $10 \mathrm{~min}$ at each temperature.

The Baeyer test was adopted to check for certain unsaturated olefin species produced during the $n$-butane isomerization. The reaction gases exiting the reactor were passed through a potassium permanganate aqueous solution with $5 \mathrm{ml}$ of $0.5 \mu \mathrm{M}$ and the timedependent UV-vis experiment was monitored with a Hitachi U3310 spectrophotometer.

\subsection{Catalytic study}

Catalytic reaction was carried out in a fixed bed continuous flow quartz reactor at atmospheric pressure. Each catalyst (usually $1.0 \mathrm{~g}$ ) was first pressed into 10-20 mesh size pellets and mixed with quartz sand. It was then pretreated under an air flow at $450{ }^{\circ} \mathrm{C}$ for $3 \mathrm{~h}$, and then pre-reduced with $\mathrm{H}_{2}$ at $300{ }^{\circ} \mathrm{C}$ for $1 \mathrm{~h}$. After flushing the system with $\mathrm{N}_{2}$ at the reaction temperature for $0.5 \mathrm{~h}$, the reaction was started by introducing a mixture of $n$-butane and $\mathrm{H}_{2}\left(n-\mathrm{C}_{4}: \mathrm{H}_{2}=1: 10, \mathrm{v} / \mathrm{v}\right)$ at a total inlet flow rate of $15.5 \mathrm{ml} \mathrm{min}{ }^{-1}$. The reaction product was analyzed using an on-lined Agilent $6890 \mathrm{~N}$ gas chromatograph equipped with a flame ionization detector and a $60 \mathrm{~m} \mathrm{DB}-1$ column.

\section{Results and discussion}

\subsection{Texture properties of the catalysts}

Textural properties of various sulfated mesoporous zirconia catalysts, including alumina or gallium or without any promoters, were characterized by X-ray diffraction and $\mathrm{N}_{2}$ adsorptiondesorption isotherm. X-ray diffraction patterns (not shown here) for the mesoporous zirconia catalysts generally exhibited a single broad peak at $\sim 1.0^{\circ}$ due to their disordered mesostructure, while the angle peaks show the tetragonal structure of zirconia. It has been shown that surface area and mesoporosity do matter in the catalytic activity of SZ [17]. Thus we use mesoporous zirconia as templated by CTAB $[11,15]$. This leads to high surface area and many mesopores, which are advantageous to transport of reactants. In Table 1, one can see that the nanoparticle form of Al-promoted SZ catalyst has a surface area of $73 \mathrm{~m}^{2} / \mathrm{g}$ which is normal compared to other reported results [18]. All the mesoporous samples in Table 1 show about twice the surface area compared with that of 3AS/Z-NP. This leads to a higher loading of sulfur (Table 1).

The calcination temperature was also shown to be important for higher catalytic activity [19]. Previously, we used mesoporous sulfated zirconia catalysts calcined at $630{ }^{\circ} \mathrm{C}$ to give the optimum 
Table 1

Elemental analyses, texture properties, and catalytic results of catalysts.

\begin{tabular}{|c|c|c|c|c|c|c|}
\hline \multirow[t]{2}{*}{ Catalyst $^{\mathrm{a}}$} & \multirow[t]{2}{*}{ Surface area $\left(\mathrm{m}^{2} / \mathrm{g}\right)^{\mathrm{b}}$} & \multirow[t]{2}{*}{ Pore volume $\left(\mathrm{cm}^{3} / \mathrm{g}\right)$} & \multirow[t]{2}{*}{ Pore diameter $(\AA)$} & \multicolumn{3}{|c|}{ Loading $(w t \%)^{c}$} \\
\hline & & & & $\mathrm{Ga}$ & $\mathrm{Al}$ & $\mathrm{S}$ \\
\hline $3 \mathrm{GS} / \mathrm{MP}-\mathrm{ZrO}_{2}$ & 148.0 & 0.10 & 29.9 & 3.40 & - & 3.95 \\
\hline $2 \mathrm{GS} / \mathrm{MP}-\mathrm{ZrO}_{2}$ & 137.4 & 0.08 & 30.7 & 2.30 & - & 2.95 \\
\hline $1 \mathrm{GS} / \mathrm{MP}-\mathrm{ZrO}_{2}$ & 139.1 & 0.09 & 30.2 & 0.90 & - & 1.79 \\
\hline $3 \mathrm{AS} / \mathrm{MP}-\mathrm{ZrO}_{2}$ & 151.2 & 0.11 & 31.3 & - & 2.20 & 3.83 \\
\hline 2AS/MP-ZrO & 150.8 & 0.10 & 31.0 & - & 1.45 & 2.89 \\
\hline $3 \mathrm{~S} / \mathrm{MP}-\mathrm{ZrO}_{2}$ & 121.6 & 0.08 & 29.3 & - & - & 0.29 \\
\hline $\mathrm{MP}-\mathrm{ZrO}_{2}$ & 144.0 & 0.12 & 32.1 & - & - & - \\
\hline 3AS/Z-NP & 73.0 & - & - & - & 2.11 & 3.61 \\
\hline
\end{tabular}

a All catalysts above were calcined at $630{ }^{\circ} \mathrm{C}$ for $5 \mathrm{~h}$.

b Determined from $\mathrm{N}_{2}$ adsorption-desorption isotherm at $77 \mathrm{~K}$.

c Determined from ICP-AES and EA.

catalytic activity in the $n$-butane isomerization reaction [15]. When one compared the effects on surface area and pore sizes, the loadings of $\mathrm{Al}$ and $\mathrm{Ga}$ give similar results. A finding in our elemental analysis study is that the amount of $\mathrm{Ga}$ or $\mathrm{Al}$ loaded onto the catalyst has a direct influence on the amount of sulfur in the catalyst. From the sulfur content in Table 1, one can see that both $\mathrm{Al}$ and $\mathrm{Ga}$ increase the sulfur loading in a roughly similar fashion. Thus, we conclude that the effects of $\mathrm{Al}$ and Ga are quite similar in affecting the textural properties and the loadings of sulfur. Both increase the surface area and the retention of sulfur in a similar fashion.

\subsection{Catalyst properties and catalytic performance}

To obtain some idea on the catalytic performance of various sulfated zirconia catalysts, we turned to $n$-butane isomerization reaction as the test reaction for the sulfated zirconia catalyst system. Under our standard reaction conditions (see Section 2), the main product in $n$-butane isomerization was isobutane (selectivity $>85 \%$ at $250{ }^{\circ} \mathrm{C}, \quad n$-butane $/ \mathrm{H}_{2}=1 / 10 \quad(\mathrm{v} / \mathrm{v})$, and $0.62 \mathrm{~h}^{-1}$ WHSV). The selectivity for isobutane was higher if the reaction temperature was lowered to $200{ }^{\circ} \mathrm{C}$, even to $100{ }^{\circ} \mathrm{C}$.

Fig. 1 compares the catalytic activities of some selected GS/MP$\mathrm{ZrO}_{2}, \mathrm{AS} / \mathrm{MP}-\mathrm{ZrO}_{2}$, and $3 \mathrm{AS} / \mathrm{Z}-\mathrm{NP}$, and that of un-doped $\mathrm{MP}-\mathrm{ZrO}_{2}$ support in $n$-butane isomerization reaction at $250{ }^{\circ} \mathrm{C}$. The effects of $\mathrm{Ga}$ and $\mathrm{Al}$ promoters on the catalytic performance were investigated by varying their loading. For most catalysts, the activity decays (but not too seriously) during the initial $120 \mathrm{~min}$ of reaction and then reaches a steady state. One can see that the

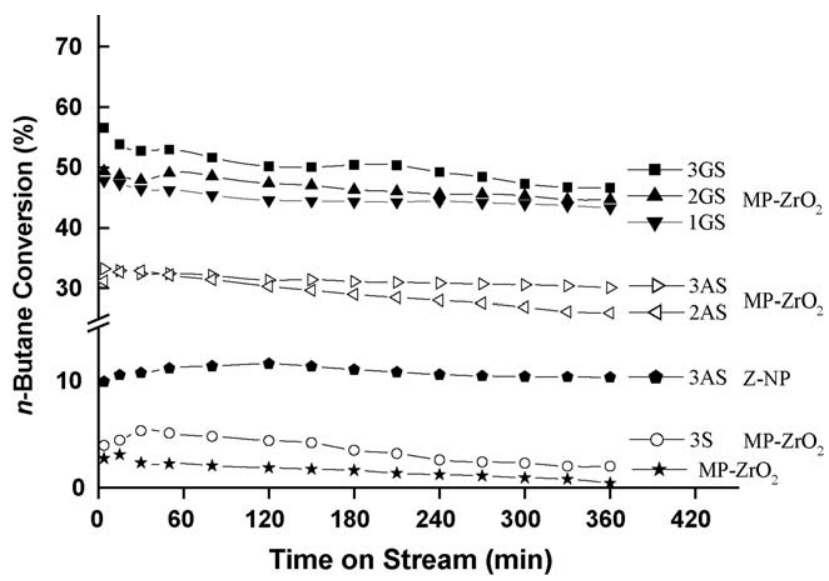

Fig. 1. The catalytic conversion of a serious of sulfated zirconia catalysts calcined at $630^{\circ} \mathrm{C}$. Reaction conditions: reaction temperature $=250{ }^{\circ} \mathrm{C}, n$-butane $/ \mathrm{H}_{2}=1 / 10$ and WHSV $=0.62 \mathrm{~h}^{-1}$. butane conversion of $3 \mathrm{GS} / \mathrm{MP}-\mathrm{ZrO}_{2}$ is nearly twice that of $3 \mathrm{AS} / \mathrm{MP}$ $\mathrm{ZrO}_{2}$ (best Al promoted catalyst) and much higher than that of unpromoted sulfated mesoporous zirconia catalyst (3S/MP- $\mathrm{ZrO}_{2}$ ).

In addition, the influence of catalyst support on the catalytic activity was also checked by comparing sulfated zirconia with both mesoporous and dense-phase nanoparticle supports (denoted by "Z-NP"). Since the effective gallium active sites are directly proportional to the surface area of the support, the catalytic performances of catalysts with $\mathrm{MP}-\mathrm{ZrO}_{2}$ structure are higher than that with Z-NP, as expected.

\subsection{Surface acidity}

In our previous work, we had shown that the Brønsted acid sites played a very important role in the $n$-butane isomerization reaction $[11,15]$. As these sites are involved directly in the formation of carbenium ion, which is an important intermediate in allowing the following oligomerization processes to proceed, the sites have a direct influence on the initial activity and coke formation of $\mathrm{GS} / \mathrm{MP}-\mathrm{ZrO}_{2}$ catalyst in butane isomerization. Therefore, an understanding of the acidity of these catalysts is of primary importance.

In order to study the Brønsted acidity of GS/MP- $\mathrm{ZrO}_{2}$ catalysts and to compare the results with the corresponding previously studied alumina-promoted catalysts $\left(\mathrm{AS} / \mathrm{MP}-\mathrm{ZrO}_{2}\right)$, we adopted TPD-MS and in situ DRIFT techniques that are commonly used in such work. Ammonia was chosen as the probe molecule for the distribution of acid sites on these catalysts.

We first compared the amount and strength of the acid sites in $3 \mathrm{GS} / \mathrm{MP}-\mathrm{ZrO}_{2}, 3 \mathrm{AS} / \mathrm{MP}-\mathrm{ZrO}_{2}$, and $3 \mathrm{~S} / \mathrm{MP}-\mathrm{ZrO}_{2}$ samples by mass spectra detection of temperature programmed desorption of ammonia ( $\mathrm{NH}_{3}$-TPD-MS) (Fig. 2). The ammonia TPD pattern appears to be similar to those reported before by other researchers [18]. The TPD peak at very high temperature (above $700{ }^{\circ} \mathrm{C}$ ) is due to ammonia-induced decomposition of sulfate group. The TPD peaks at lower temperature can be used for qualitative investigation of the strength of the acid sites. Two desorption maxima are observed: (a) a broad peak at $200-400{ }^{\circ} \mathrm{C}$ due to weak acidic sites of wide distribution of strengths and (b) a shoulder near $500{ }^{\circ} \mathrm{C}$ due to stronger acidic sites. The two catalysts, $3 \mathrm{GS} / \mathrm{MP}-\mathrm{ZrO}_{2}$ and $3 \mathrm{AS} / \mathrm{MP}-$ $\mathrm{ZrO}_{2}$ catalysts, show similar acidity in both strengths and amounts (the integrated intensity of the $\mathrm{NH}_{3}$ desorption profiles in 3GS/MP$\mathrm{ZrO}_{2}$ is actually a little lower than that of $\left.3 \mathrm{AS} / \mathrm{MP}-\mathrm{ZrO}_{2}\right)$. On the other hand, unpromoted $3 \mathrm{~S} / \mathrm{MP}-\mathrm{ZrO}_{2}$ catalyst has much less surface acidity. In particular, the shoulder at $500{ }^{\circ} \mathrm{C}$ due to stronger acidic sites almost disappeared.

The important feature is the relatively strong $\mathrm{NH}_{3}$ desorption peak centered at $490^{\circ} \mathrm{C}$ which falls within the temperature range of strong acid catalysts such as in zeolites. Previously, we have shown that the strong Brønsted acid sites in our AS/MP- $\mathrm{ZrO}_{2}$ 


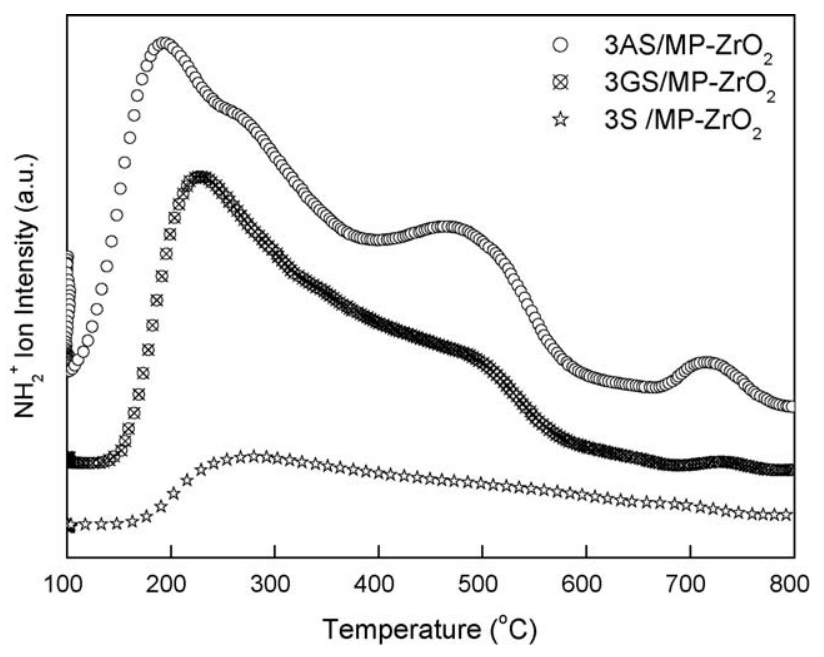

Fig. 2. $\mathrm{NH}_{3}-\mathrm{TPD}$ profiles of $3 \mathrm{AS} / \mathrm{MP}-\mathrm{ZrO}_{2}, 3 \mathrm{GS} / \mathrm{MP}-\mathrm{ZrO}_{2}$, and $3 \mathrm{~S} / \mathrm{MP}-\mathrm{ZrO}_{2}$ catalysts.

catalysts are due to isomorphous substitution of the framework $\mathrm{Zr}^{4+}$ by $\mathrm{Al}^{3+}$ in our catalyst system [15]. Recently, Pereira et al. found that isomorphous substitution of the framework $\mathrm{Zr}^{4+}$ by $\mathrm{Fe}^{3+}$ gives strong acidity in Fe-promoted sulfated zirconia [20]. We believe that $\mathrm{Ga}^{3+}$ ions play similar roles in substitution of $\mathrm{Zr}^{4+}$ ions in $\mathrm{GS} / \mathrm{MP}-\mathrm{ZrO}_{2}$. In the profile of $3 \mathrm{GS} / \mathrm{MP}-\mathrm{ZrO}_{2}$, this peak is somewhat less prominent, which may be due to the larger size of $\mathrm{Ga}^{3+}$ with respect to $\mathrm{Al}^{3+}$ making it less efficient in undergoing such substitution processes.

The in situ DRIFT technique was employed for obtaining further information on the relative strengths of the Brönsted and Lewis acid sites on these catalysts. Fig. 3 shows the DRIFT spectra of these catalysts after the desorption of surface-adsorbed $\mathrm{NH}_{3}$ at different temperatures. Two types of acid sites were found on these catalysts: namely, the Brønsted acid sites (B) and the Lewis acid sites (L). The assignment of IR bands was made according to the published works $[15,21]$. The band at $1609 \mathrm{~cm}^{-1}$ corresponds to the asymmetric $\mathrm{N}-\mathrm{H}$ deformation mode $\left(\delta_{\text {as }}\right)$ of $\mathrm{NH}_{3}$ coordinated to the Lewis acid sites. Another intense band at $1428 \mathrm{~cm}^{-1}$ and the weak band at $1675 \mathrm{~cm}^{-1}$ correspond to the $\delta_{\mathrm{s}}$ and $\delta_{\text {as }}$ of $\mathrm{NH}_{4}{ }^{+}$ formed on the Brønsted acid sites, respectively. The bands in the region below $1373 \mathrm{~cm}^{-1}$ are mainly due to the lattice vibrations of

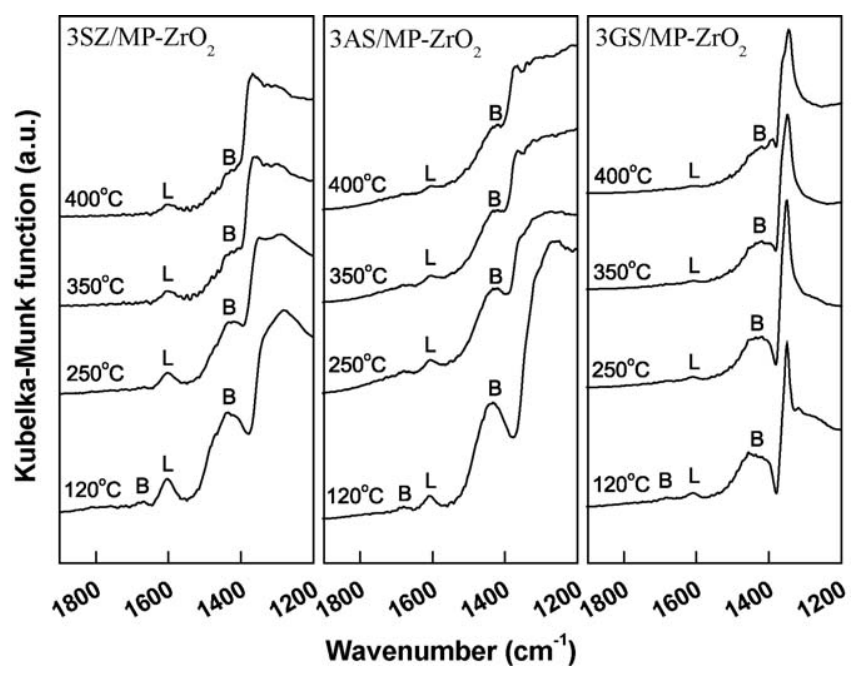

Fig. 3. DRIFT spectra of the adsorption of $\mathrm{NH}_{3}$ at $120^{\circ} \mathrm{C}$ on $3 \mathrm{~S} / \mathrm{MP}-\mathrm{ZrO}_{2}, 3 \mathrm{AS} / \mathrm{MP}-$ $\mathrm{ZrO}_{2}$, and $3 \mathrm{GS} / \mathrm{MP}-\mathrm{ZrO}_{2}$ catalysts, followed by desorption at $250,350,400{ }^{\circ} \mathrm{C}(\mathrm{B}$ : Brønsted acid sites and L: Lewis acid sites).
$\mathrm{m}-\mathrm{ZrO}_{2}$. One can see there are more Brønsted acid sites in 3AS/MP$\mathrm{ZrO}_{2}$ than in the other two catalysts, judging from the peak intensity. Besides, it also retained more chemisorbed ammonia as the catalyst was heated to $400{ }^{\circ} \mathrm{C}$ than the other catalysts. In other words, $3 \mathrm{AS} / \mathrm{MP}-\mathrm{ZrO}_{2}$ has more strong Brønsted acid sites than either $3 \mathrm{GS} / \mathrm{MP}-\mathrm{ZrO}{ }_{2}$ or $3 \mathrm{~S} / \mathrm{MP}-\mathrm{ZrO}_{2}$.

Upon desorption at $400{ }^{\circ} \mathrm{C}, \mathrm{NH}_{4}{ }^{+}$is the main species remaining. Indeed, the strength of the Brønsted acid sites in 3AS/MP- $\mathrm{ZrO}_{2}$ and $3 \mathrm{GS} / \mathrm{MP}-\mathrm{ZrO}_{2}$ catalysts is higher than that of the Lewis acid sites. It follows that $3 \mathrm{AS} / \mathrm{MP}-\mathrm{ZrO}_{2}$ has more strong Brønsted acid sites than $3 \mathrm{GS} / \mathrm{MP}-\mathrm{ZrO}_{2}$ and $3 \mathrm{~S} / \mathrm{MP}-\mathrm{ZrO}_{2}$ do. Certainly, sulfated mesoporous zirconia catalyst promoted by aluminum brings even greater contributions to the acidity of the catalyst than that by gallium under the present metal loadings.

It is worth mentioning that $3 \mathrm{GS} / \mathrm{MP}-\mathrm{ZrO}_{2}$ catalyst has relatively higher catalytic activity than $3 \mathrm{AS} / \mathrm{MP}-\mathrm{ZrO}_{2}$ notwithstanding the fact that it has lower surface acidity as revealed by TPD and DRIFT analysis. Focusing only on the acidity enhancement by alumina or gallium promoters seems to be contradictory to the results of catalysis in isomerization reaction. Thus in next section, we examine the redox properties of $3 \mathrm{GS} / \mathrm{MP}-\mathrm{ZrO}_{2}$ catalyst and correlate them with its catalytic performance.

\subsection{Redox measurements}

Previously, the redox properties of sulfated zirconia had been correlated to the activation of $n$-alkane $[13,14]$. A bifunctional catalysis mechanism (initiation by redox processes followed by acid catalysis) was proposed and used to explain the differences in catalytic activity between sulfated zirconia and Fe-Mn promoted sulfated zirconia [22]. For studies of the effect of Ga on the redox properties of sulfated mesoporous zirconia, $\mathrm{H}_{2}$-TPR technique was used. The redox characteristics of $3 \mathrm{GS} / \mathrm{MP}-\mathrm{ZrO}_{2}$ were evaluated and compared to those of the $3 \mathrm{AS} / \mathrm{MP}-\mathrm{ZrO}_{2}$ and $3 \mathrm{~S} / \mathrm{MP}-\mathrm{ZrO}_{2}$ samples.

A TPR instrument equipped with a quadrupole mass spectrometer was employed to investigate the effects of gallium and alumina promoters on the redox properties of sulfated mesoporous zirconia catalysts. TPR profiles in the temperature range from 100 to $850{ }^{\circ} \mathrm{C}$ and the relevant mass analyses are shown in Fig. 4 . The $3 \mathrm{~S} / \mathrm{MP}-\mathrm{ZrO}_{2}$ sample (Fig. 4(c)) displays a reduction peak with a maximum centered at $\sim 665^{\circ} \mathrm{C}$. The Al-promoted catalysts 3AS/ $\mathrm{MP}-\mathrm{ZrO}_{2}$ show a reduction peak (Fig. 4(b)), a little higher than that of $3 \mathrm{~S} / \mathrm{MP}-\mathrm{ZrO}_{2}$, with its maximum at $\sim 704{ }^{\circ} \mathrm{C}$. The higher reduction temperature of $3 \mathrm{AS} / \mathrm{MP}-\mathrm{ZrO}_{2}$ catalyst relative to $3 \mathrm{~S} / \mathrm{MP}-\mathrm{ZrO}_{2}$

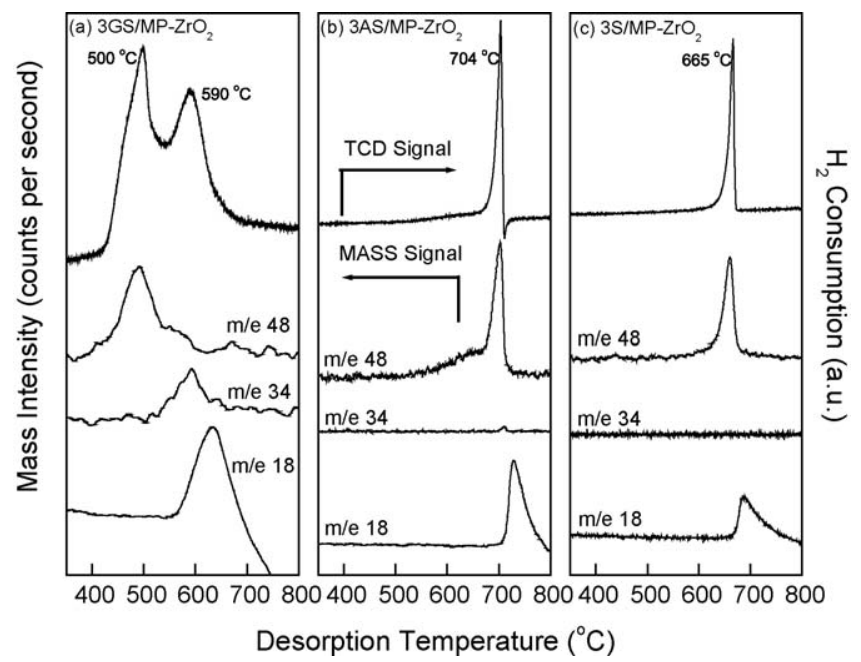

Fig. 4. $\mathrm{H}_{2}$-TPR analysis and mass spectra of the gases evolved during the TPR process. 
seems to indicate strong interactions between $\mathrm{Al}$ and $\mathrm{S}$, as we have suggested before based on elemental analysis results. However, much different from the two catalysts above, the Ga-promoted catalyst $3 \mathrm{GS} / \mathrm{MP}-\mathrm{ZrO}_{2}$ exhibits a strong reduction peak shifted to lower temperature with two maxima of different intensity, centered at 500 and $590{ }^{\circ} \mathrm{C}$, respectively.

The TPR experiments show that the doublet reduction peaks corresponding to the reductions of $\mathrm{S}^{6+}$ species $\left(\mathrm{SO}_{4}{ }^{2-}\right)$ to $\mathrm{S}^{4+}\left(\mathrm{SO}_{2}\right)$ and to $\mathrm{S}^{2-}\left(\mathrm{H}_{2} \mathrm{~S}\right)$ species respectively. In the above cases, most of the $\mathrm{SO}_{4}{ }^{2-}$ species were reduced to $\mathrm{SO}_{2}$ (detected at both $m / e=64$ and 48); however, except for the $3 \mathrm{GS} / \mathrm{MP}-\mathrm{ZrO}_{2}$ catalyst, no obvious formation of $\mathrm{H}_{2} \mathrm{~S}$ ( $m / e$ 34) were detected in the cases of $3 \mathrm{~S} / \mathrm{MP}-\mathrm{ZrO}_{2}$ and $3 \mathrm{AS} / \mathrm{MP}-\mathrm{ZrO}_{2}$, which suggests a much greater enhancement of sulfate reduction by $\mathrm{Ga}$. In addition, the mass spectra peak at $m / e$ 18 indicates $\mathrm{H}_{2} \mathrm{O}$ desorbing from the surfaces of catalysts during the $\mathrm{H}_{2}$-TPR process. Sauer and co-workers [13] have successfully shown that butene, water, and sulfur dioxide species were formed during $n$-butane isomerization on sulfated zirconia catalysts through oxidative dehydrogenation of $n$-butane. In our case, the formation of water ( $m / e$ 18) shows that the amount of surface water produced by oxidative dehydrogenation of $n$-butane decreased in the order of $3 \mathrm{GS} / \mathrm{MP}-\mathrm{ZrO}_{2}>3 \mathrm{AS} / \mathrm{MP}-\mathrm{ZrO}_{2}>3 \mathrm{~S} / \mathrm{MP}-$ $\mathrm{ZrO}_{2}$. This phenomenon suggests that gallium is likely to play more the role of a redox promoter rather than an acid promoter like aluminum.

Fig. 5 illustrates in situ DRIFT spectra of the calcined 3GS/MP$\mathrm{ZrO}_{2}$ catalyst, before and after activation, and upon adsorption and desorption of butane at various temperatures. Before activation, the spectra are typical of hydrated surfaces with adsorbed water peaks over the $1600-1700 \mathrm{~cm}^{-1}$ range. Activation process in a dry air flow results in strong reduction of this broad band, consistent with dehydration, and the spectrum of the activated sample exhibits an distinctive band at $1390 \mathrm{~cm}^{-1}$ (Fig. 5(b)), which is assigned to the stretching vibration of the $\mathrm{S}=\mathrm{O}$ bond in an adsorbed $\mathrm{SO}_{3}$ molecule [23]. The band at $2850-3010 \mathrm{~cm}^{-1}$ (Fig. 5(a)) after butane adsorption corresponds to butane adsorbed on $3 \mathrm{GS} / \mathrm{MP}-\mathrm{ZrO}_{2}$ surface [24]. In the initial process of desorption, the IR bands correspond to the butane molecules appeared strongly at low temperatures $\left(50{ }^{\circ} \mathrm{C}\right)$ due to a large amount of physisorption. Even so, they decrease much at $100{ }^{\circ} \mathrm{C}$ and nearly vanish above $150{ }^{\circ} \mathrm{C}$. Apparently, there is some conversion of butane already on $3 \mathrm{GS} / \mathrm{MP}-\mathrm{ZrO}_{2}$ at a low temperature between 50 and $100{ }^{\circ} \mathrm{C}$. Previously, Klose et al. studied DRIFT spectra of butane adsorption on sulfated zirconia (SZ) and Fe- and Mn-promoted SZ (FeSZ and MnSZ). They found no reaction of butane for SZ until $200{ }^{\circ} \mathrm{C}$. In contrast, FeSZ and MnSZ show reactions at $100{ }^{\circ} \mathrm{C}$ [24]. Our Ga-promoted $\mathrm{MP}-\mathrm{ZrO}_{2}$ is more reactive at a lower temperature.

Another interesting feature in Fig. 5 is that $3 \mathrm{GS} / \mathrm{MP}-\mathrm{ZrO}_{2}$ catalyst with its stretching vibration of the $\mathrm{S}=\mathrm{O}$ bond located at $1390 \mathrm{~cm}^{-1}$ shifted downward to $1370 \mathrm{~cm}^{-1}$ when exposed to butane molecules. As the desorption temperature increased, the vibration band shifted upward in the range of $1370-1384 \mathrm{~cm}^{-1}$. This phenomenon suggests that there are certain kinds of interaction between butane molecules and the sulfate sites on $3 \mathrm{GS} / \mathrm{MP}-\mathrm{ZrO}_{2}$ catalyst during the isomerization reaction. It is reasonable for us to suggest that, on a $3 \mathrm{GS} / \mathrm{MP}-\mathrm{ZrO}_{2}$ catalyst, a labile $\mathrm{SO}_{3}$ surface species is likely to be the active site involved in the butane isomerization reaction. At the same time, the formation of water during desorption process is shown by the increasing intensity of the deformation band of water at $1600 \mathrm{~cm}^{-1}$ (Fig. 5(b)) with the disappearance of the adsorbed butane molecules (Fig. 5(a)). The gradual formation of water on $3 \mathrm{GS} / \mathrm{MP}-\mathrm{ZrO}_{2}$ catalyst also indicates that the butane molecules were initiated via oxidative dehydrogenation by $\mathrm{SO}_{3}$ groups, as we proposed previously in Al-promoted SZ [15]. Such $\mathrm{SO}_{3}$ species react with butane to give butene, which is the starting species for the rest of acid-catalyzed isomerization reactions:

$\mathrm{C}_{4} \mathrm{H}_{10}+\mathrm{SO}_{3} \rightarrow \mathrm{C}_{4} \mathrm{H}_{8}+\mathrm{H}_{2} \mathrm{O}+\mathrm{SO}_{2}$

Similar methods were applied to the other two samples: 3AS/MP$\mathrm{ZrO}_{2}$ and $3 \mathrm{~S} / \mathrm{MP}-\mathrm{ZrO}_{2}[15]$. The amount of produced water detected on these three catalysts versus the desorption temperatures is plotted in Fig. 6. This shows that the amount of surface water produced by oxidative dehydrogenation on catalytic surfaces

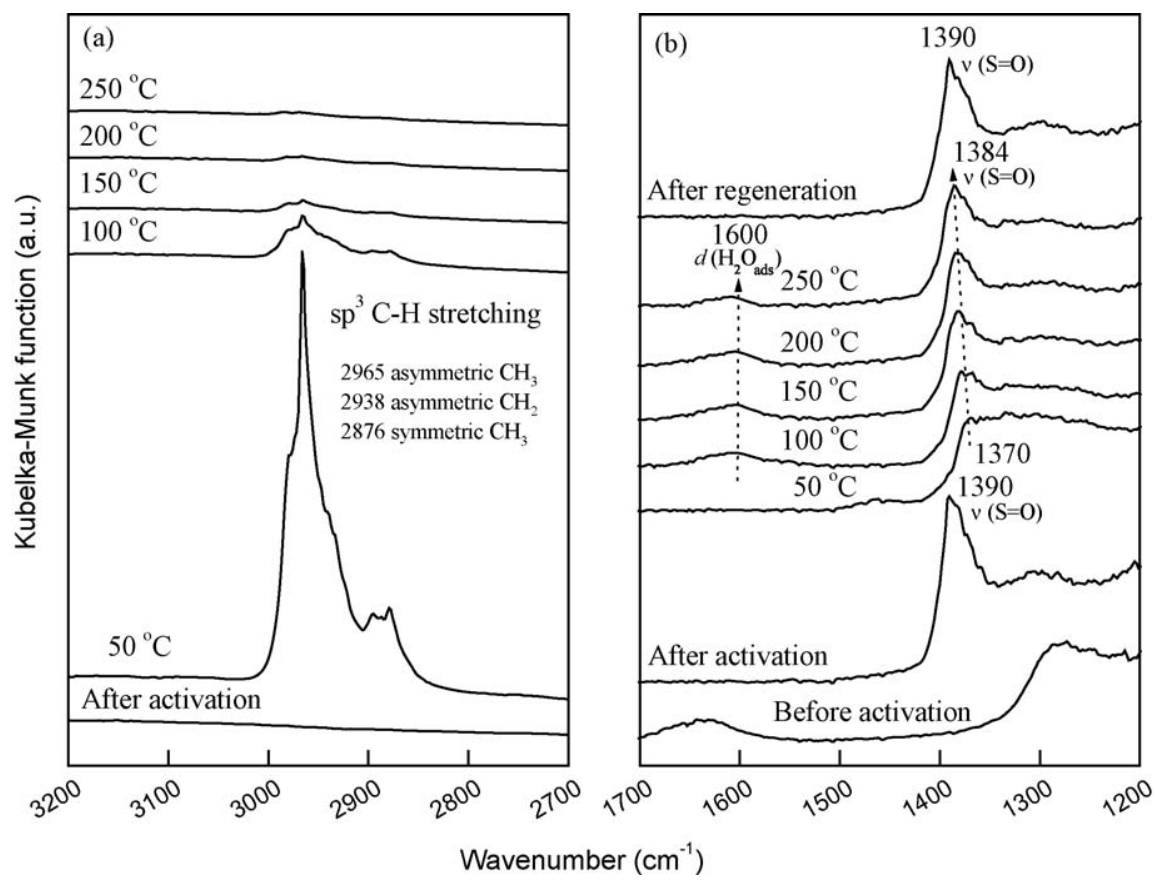

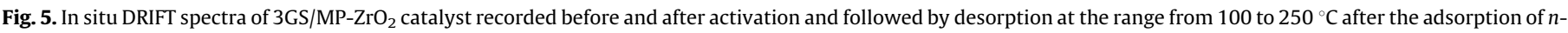
butane at $50{ }^{\circ} \mathrm{C}$ on the activated catalyst. Finally, the catalyst was regenerated with an air flow at $400{ }^{\circ} \mathrm{C}$. 


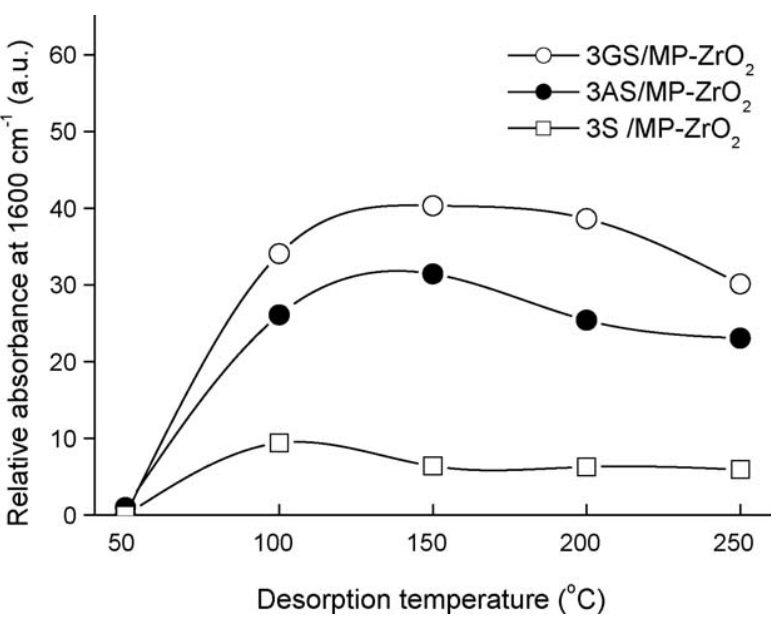

Fig. 6. Correlation between the oxidative dehydrogenation abilities of 3AS/MP$\mathrm{ZrO}_{2}, 3 \mathrm{GS} / \mathrm{MP}-\mathrm{ZrO}{ }_{2}$, and $3 \mathrm{~S} / \mathrm{MP}-\mathrm{ZrO}_{2}$ samples and the concentration of water observed by in situ DRIFT during the period of butane desorption.

decreased in the order of $3 \mathrm{GS} / \mathrm{MP}-\mathrm{ZrO}_{2}>3 \mathrm{AS} / \mathrm{MP}-\mathrm{ZrO}_{2}>3 \mathrm{~S} / \mathrm{MP}-$ $\mathrm{ZrO}_{2}$. The correlation between the intensity of the deformation band of water and the increase of catalytic activity of butane isomerization indicates that the catalytic performance increases in direct proportion with the amount of butane oxidized to butene.

Finally, as previously done in Ref. [15] for Al-promoted SZ, we employed the Baeyer test - a simple method to check for the presence of alkenes with aqueous potassium permanganate $\left(\mathrm{KMnO}_{4}\right)$ - to explore whether certain unsaturated olefin species were produced upon interacting butane with our catalysts in the initiating step of butane isomerization. Since $\mathrm{MnO}_{4}{ }^{-}$is purple and $\mathrm{MnO}_{2}$ is light brown, this color change can be easily used to assay for the presence of alkenes. Fig. 7 manifests the corresponding evolution of UV-vis spectra of $\mathrm{KMnO}_{4}$ aqueous solution at room temperature upon reacting with the effluent of butane passing through the catalyst. Potassium permanganate is a powerful oxidant and we can attribute the formation of $\mathrm{MnO}_{2}$ to the direct redox reaction between olefin species and $\mathrm{KMnO}_{4}$. With the elapsed reaction time, it can be easily seen that three peaks at about 315,525 , and $545 \mathrm{~nm}$, which originated from $\mathrm{KMnO}_{4}$, gradually disappeared with the concurrence of a new peak shifted to $370 \mathrm{~nm}$, which indicated the formation of $\mathrm{MnO}_{2}$ aqueous solution. One notes that the spectra corresponding to $\mathrm{KMnO}_{4}$ reduction to $\mathrm{MnO}_{2}$ by the species generated from the $3 \mathrm{GS} / \mathrm{MP}-\mathrm{ZrO}_{2}$ catalyst change much more than that for the other catalyst 3AS/ $\mathrm{MP}-\mathrm{ZrO}_{2}$ at the same condition. The difference shows that sulfated mesoporous zirconia promoted by gallium possesses higher redox ability resulting in more butene species, the crucial intermediate during $n$-butane isomerization, than those from alumina-promoted catalyst.
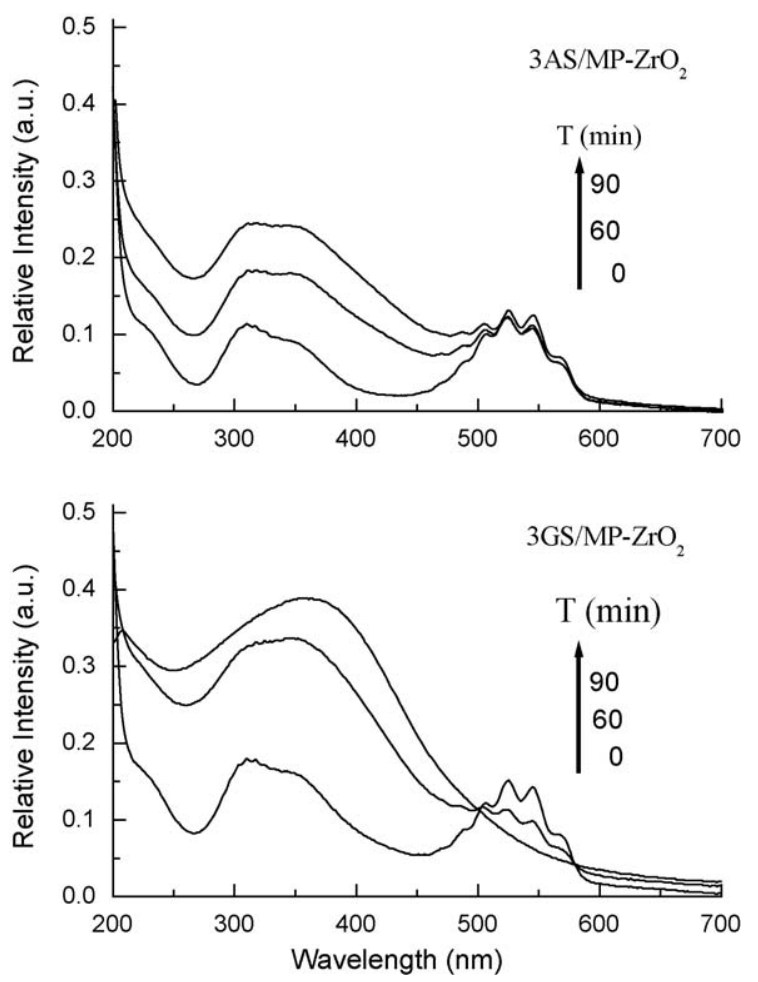

Fig. 7. Time-dependent UV-vis spectra of $\mathrm{KMnO}_{4}$ aqueous solution used to check certain unsaturated olefin species produced by $3 \mathrm{AS} / \mathrm{MP}-\mathrm{ZrO} \mathrm{r}_{2}$ and $3 \mathrm{GS} / \mathrm{MP}-\mathrm{ZrO}_{2}$ samples during the $n$-butane isomerization.

promotional effect of Al. Let us first summarize the effect of Ga and Al loadings on the structure and composition of the catalyst. From Table 1 , one can see that both $\mathrm{Ga}$ and $\mathrm{Al}$ increase the sulfur loading. The increased sulfate groups have four consequences: (1) stabilizing the active tetragonal crystalline phase of zirconia, (2) increasing the total surface area, (3) enhancing the Brønsted acidity, and (4) increasing the oxidative dehydrogenation [15]. The first two effects ((1) and (2)) have been extensively discussed before, so we will not deal with them here. The last two factors, acidity and redox properties, are in fact more important because they are directly related to the reaction mechanism. For the purpose of discussion here, let us now examine a simplified mechanism shown below [25]. The first step (1) is the dehydrogenation step to form butene. Then step (2) follows on an acid site to produce the carbenium ion. Step (3), the isomerization chain reaction, is rather complex. It requires surface acidity. We ignore details in the isomerization chain reaction, either monomolecular or bimolecular. But a linear chain reaction is involved in step (3) which generates another butane to start at step (2) again. The final hydride transfer (step (4)) gives iso-butane.
$(2)$

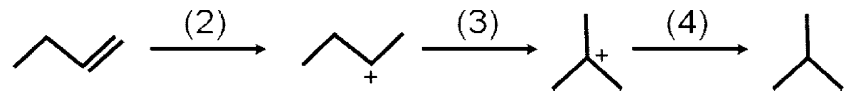

\section{Discussions}

In this section, we would like to discuss the origin of the excellent promotional effect of $\mathrm{Ga}$ and $\mathrm{Al}$ on sulfated zirconia in the isomerization of butane. Since we have just investigated recently in great detail the case of Al-promotion [15], the discussions here will be mainly focused on the case of Ga as compared with the
In principle, one could have infinite chain length and $100 \%$ selectivity; that is, for every isobutene formed, another olefinic species may be formed to continue the chain. Then, step (1) would not be very important. In reality, continuous generation of olefinic species is important for sustained activity because of finite chain length and of coke formation blocking some active sites. From kinetic considerations, a steady rate of isomerization is the result of 
balancing the rates of dehydrogenation step (1) and acid-catalyzed isomerization step (3). For a steady activity, a high rate of dehydrogenation demands a matching high rate of isomerization. If the rate of dehydrogenation is higher than the isomerization/ desorption rate initially, coke will form, leading to deactivation. On the other hand, if the dehydrogenation rate is too low, the surface acid sites are under-used.

With the above analysis, we can then try to understand the differences in catalytic activities between $\mathrm{Ga}$ and $\mathrm{Al}$ promoted sulfated zirconia. Specifically, when one compares the two catalysts $3 \mathrm{GS} / \mathrm{MP}-\mathrm{ZrO}_{2}$ and $3 \mathrm{AS} / \mathrm{MP}-\mathrm{ZrO}_{2}$, one finds that they have almost identical sulfur content and surface area. As a consequence, the two catalysts, $3 \mathrm{GS} / \mathrm{MP}-\mathrm{ZrO}_{2}$ and $3 \mathrm{AS} / \mathrm{MP}-\mathrm{ZrO}_{2}$ catalysts, show very similar acidity in both strengths and amount. Then it is clear that the reason $3 \mathrm{GS} / \mathrm{MP}-\mathrm{ZrO}_{2}$ gives higher activity must be due to higher production of butene from the dehydrogenation step. For the above two catalysts, the comparisons of the redox properties by TPR, Bayer's tests of olefin production and DRIFT studies of evolved water upon oxidative dehydrogenation all indicate the higher initiation rate in step (1) in Ga-promoted SZ catalyst. Gallium oxide has been known to promote activation of $\mathrm{C}-\mathrm{H}$ bond in hydrocarbons [26]. Compared with Al-promoted SZ, the extra acid reservoir in SZ apparently could be further used when Ga-promotion leads to more production of butene and thus to carbenium intermediates.

In the past, other promoters for sulfated zirconia have been used, including Fe, Mn and Pt. However, Fe and Mn promoted SZ catalysts usually start with high initial rate but then deactivate quickly. It is known that Fe and Mn do not increase the surface acidity while promoting dehydrogenation [24,27]. This probably leads to relative over-production of surface olefin species, which then leads to coke formation. On the other hand, Ga and $\mathrm{Al}$ promotion of SZ appear to be both active in the oxidative dehydrogenation and also in the increase of surface acidity. Both steps (1) and (3) have to be increased to result in an increase of the steady rate of isomerization. Another often used promoter for SZ catalyst in isomerization is $\mathrm{Pt} / \mathrm{H}_{2}$ [28,29]. The Pt metal has been proposed to be bifunctional in providing both the dehydrogenation-hydrogenation function and in hydrogen spill-over to increase acidity [29]. However, in most of the reported studies, $\mathrm{Pt} / \mathrm{H}_{2}$ probably served more in hydrogenation rather than dehydrogenation as hydrogen served to depress the reaction rate [30].

Furthermore, Al and Ga have been found not only to increase the total amount of surface acidic sites but also to change the balance of the types of surface acidity. In our previous study of the acidity of Al-promoted sulfated zirconia [11], we have identified by XPS measurement of adsorbed pyridine three kinds of acid sites: one Lewis acid (L), one strong Brønsted (SB) and one weak Brønsted (WB) site. It was found that too much of SB often gives a high initial rate but the material quickly deactivates. A larger number of SB sites promote the initial rate of reaction. However, this will also promote coke formation. In order to sustain the reaction through the later stages of reaction, there must be many WB sites which are less susceptible to deactivation by coke formation. WB sites played an important role in the steady stages of reaction. Apparently, the optimum amount of $\mathrm{Al}$ or Ga loading would give the optimum distribution of the type of acid sites.

\section{Conclusions}

In conclusion, we have investigated the promotional effect of alumina and gallium to mesoporous SZ on the butane isomeriza- tion. There are two mechanisms of metal promotion of catalytic activities. First, in the promoted acidity, Al is a slightly better promoter than Ga, giving more acidity in mesoporous sulfated zirconia. On the other hand, both metals also promoted the redox properties in mesoporous sulfated zirconia. The doping of alumina or gallium to SZ increased the extent of sulfur retention on the surface of zirconia, which then promotes the oxidative dehydrogenation to butene and consequently the skeleton isomerization. Ga turns out to be a much stronger promoter of the redox property of SZ, giving more butene than Al-promotion. Overall, Gapromoted sulfated mesoporous zirconia gives better catalytic activity in butane isomerization than the corresponding Alpromoted sulfated mesoporous zirconia. It is important to achieve an optimum balance in the initial rate of butene formation by oxidative dehydrogenation and the subsequent rate of acidcatalyzed isomerization. Apparently, Ga-promoted sulfated zirconia is the best catalyst in achieving such a fine balancing act. The GSZ catalyzed isomerization reaction also does not need any Pt to stabilize its long term activity. The Pt-free catalyst is attractive as a practical industrial catalyst.

\section{Acknowledgements}

This work was supported by a grant from the National Science Council of Taiwan. We would like to acknowledge the help we received from Dr. J.H. Wang.

\section{References}

[1] M. Hino, K. Arata, Catal. Lett. 30 (1995) 25-30.

[2] Z. Gao, Y.D. Xia, W.M. Hua, C.X. Miao, Top. Catal. 6 (1998) 101-106.

[3] W. Wang, C.L. Chen, N.P. Xu, C.Y. Mou, Green Chem. 4 (2002) 257-260.

[4] C.L. Chen, S.F. Cheng, H.P. Lin, S.T. Wong, C.Y. Mou, Appl. Catal. A: Gen. 215 (2001) 21-30.

[5] J.H. Wang, C.Y. Mou, Abstr. Pap. Am. Chem. Soc. 224 (2002) U45.

[6] C.L. Chen, T. Li, S.F. Cheng, N. Xu, C.Y. Mou, Catal. Lett. 78 (2002) 223-229.

[7] C.J. Cao, S. Han, C.L. Chen, N.P. Xu, C.Y. Mou, Catal. Commun. 4 (2003) 511515.

[8] C.J. Cao, X.Z. Yu, C.L. Chen, C.Y. Mou, React. Kinet. Catal. Lett. 83 (2004) 85-92.

[9] W. Wang, J.H. Wang, C.L. Chen, N.P. Xu, C.Y. Mou, Catal. Today 97 (2004) 307313.

[10] W. Hua, Y. Xia, Y. Yue, Z. Gao, J. Catal. 196 (2000) 104-114.

[11] J.H. Wang, C.Y. Mou, Appl. Catal. A: Gen. 286 (2005) 128-136.

[12] E.A. Pidko, E.J.M. Hensen, R.A. van, Santen, J. Phys. Chem. C 111 (2007) 1306813075.

[13] X. Li, K. Nagaoka, L.J. Simon, R. Olindo, J.A. Lercher, A. Hofmann, J. Sauer, J. Am. Chem. Soc. 127 (2005) 16159-16166.

[14] X. Li, K. Nagaoka, L.J. Simon, J.A. Lercher, S. Wrabetz, F.C. Jentoft, C. Breitkopf, S. Matysik, H. Papp, J. Catal. 230 (2005) 214-225.

[15] C.C. Hwang, C.Y. Mou, J. Phys. Chem. C 113 (2009) 5212-5221.

[16] U. Ciesla, M. Fröba, G. Stucky, F. Schüth, Chem. Mater. 11 (1999) 227-234.

[17] M. Busto, K. Shimizu, C.R. Vera, J.M. Grau, C.L. Pieck, M.A. D’Amato, M.T. Causa, M. Tovar, Appl. Catal. A: Gen. 348 (2008) 173-182.

[18] K. Föttinger, K. Zorn, H. Vinek, Appl. Catal. A: Gen. 284 (2005) 69-75.

[19] X.L. Zhou, G.X. Yu, C. Tang, C.L. Li, J.A. Wang, O. Novaro, M.E. Llanos, Ma.A. CortésJácome, Catal. Lett. 124 (2008) 277-283.

[20] A.L.C. Pereira, S.G. Marchetti, A. Albornoz, P. Reyes, M. Oportus, M.C. Rangel, Appl. Catal. A: Gen. 334 (2008) 187-198.

[21] C.D. Baertsch, S.L. Soled, E. Igalesia, J. Phys. Chem. B 105 (2001) 1320-1330.

[22] C.Y. Hsu, C.R. Heimbuch, C.T. Armes, B.C. Gates, J. Chem. Soc. Chem. Commun. (1992) 1645-1646.

[23] K. Föttinger, E. Halwax, H. Vinek, Appl. Catal. A: Gen. 301 (2006) 115-122.

[24] B.S. Klose, F.C. Jentoft, R. Schlögl, I.R. Subbotina, V.B. Kazansky, Langmuir 21 (2005) 10564-10572.

[25] X. Li, K. Nagaoka, L.J. Simon, R. Olindo, J.A. Lercher, J. Catal. 232 (2005) 456466.

[26] V.B. Kazansky, I.R. Subbotina, A.A. Pronin, R. Schlögl, F.C. Jentoft, J. Phys. Chem. B 110 (2006) 7975-7978.

[27] B.S. Klose, F.C. Jentoft, P. Joshi, A. Trunschke, R. Schlögl, I.R. Subbotina, V.B. Kazansky, Catal. Today 116 (2006) 121-131.

[28] K. Zorn, K. Föttinger, E. Halwax, H. Vinek, Top. Catal. 46 (2007) 93-100.

[29] T. Løften, E.A. Blekkan, Appl. Catal. A: Gen. 299 (2006) 250-257.

[30] U.B. Demirci, F. Garin, J. Mol. Catal. A 271 (2007) 216-220. 